\title{
O PROCESSO CIVILIZADOR E AS CONFIGURAÇÕES CEGAS NO PROJETO DE ASSENTAMENTO TARUMÃ MIRIM
}

\author{
THE CIVILIZING PROCESS AND THE BLIND SETTINGS IN THE TARUMÃ MIRIM \\ SETTLEMENT PROJECT
}

\author{
A.M. V. DEMETRIO ${ }^{1,}$, R. M. S. P. BARBOSA ${ }^{1}$ \\ 1 Universidade Federal do Amazonas, AM, Brasil. \\ Programa de Pós-graduação em Sociedade e Cultura na Amazônia, Brasil
}

\author{
ARTICLE INFO \\ Article history: \\ Received 2018-04-13 \\ Accepted 2018-04-30 \\ Available online 2018-05-02 \\ *Autor correspondente: \\ E-mail: agdademetrio@gmail.com
}

\begin{abstract}
Palavras-chave: Configurações sociais. Processo civilizatório. Indivíduos. Sociedade. Configurações cegas.
\end{abstract}

Keywords: Social settings. Civilizing process. Individuals. Society. Blind settings.

RESUMO. O processo civilizador se caracteriza onde as estruturas emocionais e comportamentais incorporam-se, modificando as transformações que acontecem na sociedade, inserindo-se nas interrelações sociais, integrando-se no cotidiano dos indivíduos. Essas normatizações comportamentais são adquiridas desde a primeira infância, passando aos ensinamentos escolares, e estendendo-se nos relacionamentos profissionais, em uma rede figurativa de relacionamentos, formando as configurações sociais. As regras sociais deste século diferem-se daquelas dos séculos anteriores, porque o que antes era aceito como normal e social, foram se readequando, se modificando. Isto é o autocontrole como fruto do processo civilizatório norteando comportamentos, quer perante a sociedade, quer perante a si próprio. Essas relações geram as interdependências, que formam as junções entre os indivíduos, interligando-os em suas ações, sem possibilidades de separar o "eu" do "nós" nas responsabilidades. Pesquisa etnográfica, técnica da observação participante, análises quanti e qualitativa dos dados coletados com 70 assentados entrevistados. A pesquisa demonstrou que essas interligações pessoais unem imperceptivelmente os seres humanos, porque todos convivem numa mesma configuração social. A configuração cega nos remete ao conceito que os comportamentos sociais do "agora" podem influenciar, e modificar, os parâmetros sociais do "amanhã". Nesse viés do pensamento, analisamos os aspectos do êxodo rural dos jovens do projeto de assentamento Tarumã Mirim, zona rural de Manaus-AM, rompendo o processo sucessório no que concerne à agricultura familiar, nos instigando a questionamentos acerca do futuro daquele assentamento, relacionado às questões produtivas. Polos educacionais e balneabilidade romperiam o ciclo do êxodo rural dos jovens, fomentando perspectivas de um futuro diferente ao que ora desponta.

\begin{abstract}
The civilizing process characterized itself when the emotional and behavioral structures incorporate themselves, modifying the transformations that happen in the society, inserting itself in the social inter-relations, integrate itself in the individuals' day by day. These behavioral standardizations are acquired since the early childhood, passing to the school teachings, and extending themselves in the professional relationships, in a figurative network of relationships, forming the social settings. The social rules from this century differ themselves from those of previously centuries, because what once was accepted as normal and social, had been suiting themselves again, modifying themselves. This is the auto control as the fruit of the civilizing process guiding behaviors, either to society, either to themselves. These relations generate the interdependences, that form the junctions between the individuals, interconnecting themselves in their actions, without possibilities to separate the "me" from "us" in the responsibilities. Ethnographic research, participation observation techniques, quantitative and qualitative analyses from the collected data with 70 seated interviewed. The research demonstrate that these personal interconnections unite insensibly the human being, because everybody live together in a same social setting. The blind setting leads us to the concept that the social behaviors from "now" can influence, and modify, the social parameters of "tomorrow". In this thinking bias, we analyze the rural exodus aspects of young people from the Tarumã Mirim settlement project, rural area of Manaus-AM, breaking the succession process in what concerns to family farm,
\end{abstract}


instigate us to questionings about the future of that settlement, related to productive questions. Educational poles and enable of bathhouses would break young people's the rural exodus cycle, fomenting perspectives of a different future to the one that now dawns.

\section{INTRODUÇÃO}

O processo civilizador se caracteriza onde as estruturas emocionais e comportamentais incorporam-se, modificando as transformações que acontecem na sociedade. Essas regras inseremse em inter-relações sociais, integram-se no nosso cotidiano, pois desde cedo nos são ensinadas, em nome da boa civilidade. Elas são adquiridas desde a primeira infância, passando aos ensinamentos escolares, e estendendo-se nos relacionamentos profissionais, numa rede figurativa de relacionamentos, formando as configurações sociais. A convivência diária nos mostra que o "outro" faz parte da nossa vivência, da nossa socialização.

As estruturas sociais vivenciadas no momento atual são consequências das estruturações do passado. São comportamentos que foram se incorporando, formatando as conveniências sociais atuais. Em virtude de não serem perceptíveis quando ocorrem, denomina-se "configurações cegas", ou seja, quando estão ocorrendo não sabemos a dimensão que alterarão as estruturações sociais futuras.

Este artigo tem por objetivo compreender o processo civilizador, nas suas interdependências e inter-relações sociais dentro de um assentamento rural, e estimular as inquietações decorrentes do êxodo rural dos jovens, indicando as configurações cegas a modificar o contexto rural futuramente.

Dois aspectos nos instigaram às análises acerca do processo civilizador: $O$ que difere o processo civilizador analisado no contexto urbano e rural? Nessas indagações, quando da pesquisa de campo, durante oito meses, nos deparamos com o segundo aspecto a nos inquietar: observamos que a Comunidade Afatam, bem como todo o assentamento Tarumã Mirim, é formada predominantemente de pessoas acima dos 50 anos de idade. Poucos jovens residem de forma continuada no assentamento, comparecendo às casas dos pais somente nos finais de semana, ou às vezes esporadicamente. Ora, seguindo a trajetória biológica natural da vida, os idosos morrem. Nesse contexto, quem irá cultivar a terra, plantar e colher, se os idosos não mais estarão na lida e os jovens migraram para Manaus? Será esse um dos aspectos do processo civilizador, no âmbito das configurações cegas, nos inquietando acerca do futuro produtivo daquele assentamento.

\section{MÉTODO}

A proposta de abordagem teórico-metodológica para este trabalho se fundamentou na pesquisa quali e quantitativa, através do método etnográfico. Praticar a etnografia é estabelecer relações, selecionar informantes, transcrever textos, mapear campos, manter um diário, porque a etnografia é uma descrição densa dos fatos em análise (GEERTZ, 2008). Se a etnografia é uma descrição densa e os etnógrafos são aqueles que fazem a descrição, então a questão determinante é fazer as transcrições de forma concisa e minuciosa, tentando salvar o "dito" (GEERTZ, 2008, p. 12-15) no discurso, diferenciando as diversas interpretações observadas. Isso porque às vezes o "dito" é dito de forma que não representa a realidade vivenciada, instigado somente pelo momento da entrevista. Assim, incluir as minúcias nas descrições propicia uma aproximação entre o ocorrido e o registrado, sendo, 
portanto, essencial que os registros se concretizem tão logo tenha ocorrido o fato, a entrevista, a observação, o fato detectado (GEERTZ, 2008).

Nesse tipo de pesquisa, recomenda-se ao etnógrafo que de vez em quando deixe de lado a máquina fotográfica, lápis e caderno, e participe pessoalmente do que está acontecendo, tomando parte nas atividades, passeios, ou sentar-se com eles, ouvindo e participando das conversas (MALINOWSKI, 1978, p. 31). Também há orientações para que as narrativas etnográficas devam ser escritas na 1a pessoa, pois o olhar etnógrafo descreverá as diferenças e a variação no outro (OLIVEIRA FILHO, 1999, p. 212). A partir do dito, cito o "eu" nos momentos específicos da pesquisa de campo, retornando ao pronome na $1^{\underline{a}}$ pessoa do plural "nós" nas análises e interpretações dos dados coletados, as quais foram procedidas conjuntamente com a coautora deste trabalho.

A técnica para a coleta de dados ocorreu através da observação participante, que consiste em ver, ouvir, captar e entender as palavras e expressões (MATOS, 2015). Para tal, contamos com um informante-chave, mediador para quesitos de dúvidas ou para sanar falsas interpretações, passando ele a ser colaborador da pesquisa, seguindo também as especificações da obra de Whyte (2005). Contar com o auxílio de sujeitos pertencente à área pesquisada facilita as interpretações da observação participante, em similaridade à obra de Alves (2011), quando a observação participante daquele foi procedida conjuntamente com o informante-chave e se tratava de sujeito pertinente inserido na sociedade pesquisada. Tal informante-chave desta pesquisa foi o líder daquela comunidade e presidente da associação de moradores. Obtivemos também auxílio relevante da ex-presidente da associação, por ela residir há 15 anos na comunidade e ter sido presidente da associação por oito anos, tornando-a deveras conhecedora do ambiente, e dos aspectos socioeconômicos da área pesquisada.

A amostragem foi não probabilística, porque a escolha dos elementos foi feito de forma não aleatória, existindo um procedimento de seleção dos elementos da população segundo critérios estabelecidos pela pesquisadora (SANTOS, 2011, p. 134 - 136), dividido em grupos proporcionais ao seu tamanho. Para a pesquisa de campo, foi utilizado o gravador, e as informações foram registradas no diário de campo, cuja transcrição resultou em 199 páginas, que compuseram as bases empíricas para a dissertação.

As análises dos resultados decorreram dos resultados quantitativos das entrevistas, bem como dos dados captados através da Observação Participante, qualitativamente, no período total de oito meses, residindo no ambiente pesquisado.

\section{SUJEITO E OBJETO DA PESQUISA}

Este trabalho originou-se da pesquisa para compor a dissertação "Lazer e agricultura familiar: complementares ou antagônicos nos aspectos socioeconômicos no projeto de assentamento Tarumã Mirim?". A pesquisa de campo foi realizada no projeto de assentamento Tarumã Mirim. Tal assentamento foi criado pelo INCRA, através da Resolução no 184, de 20 de agosto de 1992, estando aquele imóvel rural inserido no Projeto Fundiário Manaus da década de 1970 e com o decorrer do processo foi-se subdividindo em diversas comunidades, dentre elas a comunidade Afatam. $\mathrm{O}$ acesso ao referido assentamento pode ser realizado via terrestre, através do Ramal do Pau-rosa, estrada secundária, à altura do KM 21 da BR 174 (sentido Manaus-Boa Vista), e via fluvial pelo Rio Negro através do igarapé Tarumã Mirim a sudoeste e a noroeste pelo Igarapé Tarumã Açu. Limita-se ao 
norte e ao sul com terras da União de competência da Superintendência da Zona Franca de Manaus (SUFRAMA). O Projeto de Assentamento Tarumã Mirim possui uma área de 42.910,76 ha (429 km²), com capacidade para assentar 1.042 famílias (INCRA/AM 1999:1; PINTO e CARVALHO, 2007).

Devido a grande extensão geográfica do assentamento, foi delimitada a área de atuação para as entrevistas com os 70 assentados e moradores, a comunidade Afatam, no referido assentamento. Existem, atualmente, 85 lotes na comunidade, os quais foram incluídos na ficha-relatório, elaborado pela associação de moradores e cedido para esta pesquisa, na qual foram descritas as identificações dos moradores, as formas de acesso, as suas produções e as respectivas classificações produtivas. Demais dados pertinentes da pesquisa, acerca dos processos sociais, abrangeram o assentamento rural, inclusive outras comunidades daquele assentamento.

Para calcular estatisticamente o tamanho da amostra, foi solicitado e obtido da Associação dos Moradores e Trabalhadores da Agricultura Familiar da comunidade (Afatam), no projeto de assentamento Tarumã Mirim, a quantidade de lotes naquela comunidade, com descrição por classificação produtiva.

A forma expressa do linguajar caboclo, registrado na pesquisa, tais quais suas pronúncias, é similar ao adotado nos trabalhos de Baldino et a.l (2015), e não tem como intensão estigmatizar o entrevistado, mas sim respeitar a forma de expressão dos mesmos, conservando a linguística original. $\mathrm{Na}$ transcrição integral ou fragmentada dos diálogos, observamos a fonética da pronúncia, para que não se perca a característica linguística regional de quem deu o depoimento. Ainda que este não seja um trabalho voltado para a análise da linguagem, ele poderá se constituir em material futuro para investigação de algum outro pesquisador nessa área, daí a importância da riqueza linguística dos depoimentos coletados.

Os dados foram coletados através de entrevista estruturada, aplicada em 70 assentados do referido projeto de assentamento, dentro dos critérios de inclusão (ser assentado pelo INCRA ou ser morador (não assentado) e residir no assentamento há mais de um ano; ser maior de 18 anos; homem ou mulher responsável pelo lote; aceitar participar da entrevista), por um período de seis meses. Para este trabalho também foi estendido a pesquisa com 15 mulheres (designadas pela sigla TRU-1 a TRU-15), fora dos critérios de inclusão, no período de dois meses, quando cozinharam para a equipe de 20 trabalhadores da Secretaria Municipal de Infraestrutura de Manaus - SEMINF, que recuperavam as vicinais daquela comunidade pesquisada.

\section{O PROCESSO CIVILIZADOR}

O processo civilizador é uma teoria. Um estudo de longo prazo que norteia como os indivíduos mudam suas formas de se comportar e sentir. Caracteriza-se quando as estruturas emocionais e comportamentais incorporam-se, moldando, modificando e transformando comportamentos que acontecem na sociedade (ELIAS, 2011). Essas regras inserem-se em interrelações sociais, integram-se no nosso cotidiano, pois desde cedo nos são ensinadas, em nome da boa civilidade. Elas são adquiridas desde a primeira infância, passando aos ensinamentos escolares, e estendendo-se nos relacionamentos profissionais, numa rede figurativa de relacionamentos, formando as configurações sociais. Os comportamentos ditados pelas emoções sem o "filtro" das regras normativas, sem controle moral, fluidas somente de instintos, remeteriam o ser humano à 
condição de irracional, afinal, o homem é "um ser plenamente biológico, mas se não dispusesse plenamente da cultura, seria um primata do mais baixo nível" (MORIN, 1999, p. 53).

As atividades humanas mais animalescas são progressivamente excluídas do palco da vida comum e investidas de sentimentos de vergonha (ELIAS, 1993), tais como defecar perante os outros, comer alimentos diretamente do chão, andar nu. A peculiar trama de independência e dependência, de necessidade e capacidade de decidir sozinho, por um lado, e de impossibilidade de decidir sozinho, por outro, devido às diversas concepções sociais, tanto emanadas de si, como em obediência norteadas pelo Estado, podem produzir tensões consideráveis, instigando os indivíduos a controlarem suas emoções.

O desejo de ser alguém por si, individualmente, interliga-se com processos externos e obstrutivos, porque as normas sociais são geridas a partir do "todo", nas aceitações coletivas. O desejo de estar inteiramente inserido na sociedade caracteriza o homem como diferente de outros animais, pois carrega sobre si o ônus e o bônus do processo civilizador (ELIAS, 1994, p. 124). O ônus porque "obriga-se" a ser um indivíduo civilizado (em detrimento às vontades individuais), e o bônus porque ele beneficia-se desse processo, controlando ações e comportamentos, permitindo uma convivência onde os direitos são respeitados, os limites sociais observados, levados pelas imposições sociais e pela necessidade de sobrevivência em comunidade. Uma responsabilidade enorme vai pesando sobre os indivíduos à medida que ele se civiliza (ELIAS, 2011), porque quanto mais evoluem, mais a sociedade Ihes cobra comportamentos civilizados, emoções controladas, ações concernentes ao que dele se espera.

Todo o estilo de sua coexistência social "leva cada vez mais a um controle geral dos afetos, à negação e transformação dos instintos" (ELIAS, 1994, p. 103). À medida que prossegue essa mudança social, os indivíduos vão se desenvolvendo, as pessoas são mais e mais instadas a esconderem-se umas das outras, ou até de si mesmas, as funções corporais ou as manifestações e desejos instintivos antes livremente expressos. À medida que o homem evolui, uma mudança no padrão de comportamento vai se adequando em conformidade com as normas sociais. Aquilo que se apresenta como um processo de individualização crescente, mas dentro das normas sociais, ou seja, o seu "amadurecimento como pessoa", é visto como um processo de civilização.

Nesse sentido, as tensões entre os ditames e proibições sociais, internalizadas como autocontrole, e os impulsos espontâneos reprimidos, esse conflito no indivíduo, essa "privação" como os sentimentos de vergonha ou embaraço - desperta a sensação de ser único nas suas emoções, fazendo parte do universo social (ELIAS, 1994, p. 103). Os excessos das explosões fortes e apaixonadas vão sendo amortecidos por restrições embutidas conservadas pelo controle social, incrustradas de modo tão profundo que não podem ser abaladas (ELIAS e DUNNING, 1992, p. 112), nos processos civilizatórios. Esses sentimentos passam a fazer parte das atitudes comportamentais das pessoas, e esses processos estendem-se em uma teia, abrangendo todo o contexto social, definindo as regras sociais atuais.

Nesses processos civilizadores, observamos dois aspectos inerentes aos seres humanos, quer em âmbito social, quer individual: a Psicogênese e a Sociogênese (ELIAS, 2011). Apesar das referências isoladas, elas estão intrinsecamente interligadas, devido à ocorrência de uma interferir e direcionar a outra. Segundo Elias (2011), a "psicogênese" é inerente aos seres humanos, altera o desenvolvimento da psique humana, norteando-o a comportamentos ditos "adequados" na sociedade, 
ou seja, a transformação que ocorre na estrutura da personalidade do ser individual. Na primeira infância, por exemplo, a criança não controla suas emoções, chora livremente, defeca e urina na roupa, etc., porém, à medida que ela vai se desenvolvendo no seu meio social, ela vai assimilando comportamentos que, se antes era tido como "engraçadinho", ou natural, ora se torna inadequado.

A "sociogênese" apresenta-se nas inúmeras transformações que ocorrem constantemente nas estruturas das sociedades, produzindo modificações nas inter-relações sociais. Desse modo, a sociogênese e a psicogênese ocorrem reciprocamente no interior dos processos históricos de longa duração, direcionando as mudanças no comportamento dos indivíduos que vão se adaptando, se remodelando, conforme os fatos históricos e sociais, ocorridas no interior das sociedades (ELIAS, 2011). Esses comportamentos individuais, que instigam às adequações sociais, vão nos "modelando" a adequar o "eu" no "nós" como sociedade. Essas modificações sociais nos estimularam ao entendimento desse processo.

\section{AS CONFIGURAÇÕES E AS INTERDEPENDÊNCIAS SOCIAIS}

As regras sociais deste século diferem-se das dos séculos anteriores, porque o que antes era aceito como normal e social, foram se readequando, se modificando. Isto é, o autocontrole como fruto do processo civilizatório norteando comportamentos, quer perante a sociedade, quer perante a si próprio. Essas relações geram as interdependências, que formam as junções entre os seres sociais, interligando-os nas suas ações, sem as possibilidades de separar o "eu" do "nós" nas responsabilidades. Essas interligações pessoais unem imperceptivelmente os seres humanos, seja nas origens das ações praticadas por "a" ou "b", ou posteriormente, porque todos convivem numa mesma configuração social. Até o "não fazer nada" encontra-se vinculado nas suas configurações sociais e interdependências, porque em algum momento anterior houve a interferência, direta ou indireta, contribuindo para aquele momento de relaxamento: na fabricação da cadeira em que esteja sentado, na fiação da rede em que esteja deitado, na vara de pesca que repousa nas margens dos rios ou igarapés. A rede de interdependência entre os seres humanos é o que nos ligam, pois o "eu" encontra-se intrinsecamente embutido nas ações praticadas por "eles", visto que muito do que "eles" praticam é, direta ou indiretamente, destinado a "mim".

No decorrer desse processo, mais e mais pessoas convivem numa crescente dependência uma das outras, interligada imperceptivelmente, como que por correntes invisíveis. Cada qual funciona como elo, numa trama de ações, de capacidades para vivenciá-las ou executá-las, se interpondo em direção a uma meta social, em uma interdependência evolutiva (ELIAS, 1994, p. 111).

Essas interdependências e inter-relações estão tão imbricadas nos indivíduos, que não há como haver um isolamento social. Se "A" fala, há a necessidade do ouvinte, para que haja a interação no diálogo, pois o monólogo não satisfaria a condição de ser sociável. Analisamos que, mesmo no desmatamento, há a participação indireta do "eu", ao utilizarmos a madeira no processo industrial final, ao adquirir os móveis para o nosso lar, as janelas e portas (de madeira) nas nossas construções, aos caibros das nossas casas, pois usufruímos desse produto, sem o conhecimento da certificação ambiental. Essa madeira utilizada foi processada através de um manejo sustentável?

No alimento saboroso da carne de animais silvestres que "eu" saboreio, há a "minha" predação consentida, por "eu" não procurar saber se aquela carne é o processo da caça predatória. No conforto de trafegabilidade automotiva que "eu" faço usufruto no ir e vir há poluição ao meio

REVES - Revista Relações Sociais 
ambiente, devido à queima de combustíveis fósseis; na aclimatação dos nossos espaços residenciais, do trabalho ou lazer, há a contribuição aos danos à camada de ozônio, decorrentes do gás utilizado nos aparelhos de ares condicionados.

Tudo isso nos remete mais uma vez às interdependências, nos interligando nas configurações sociais. Não há como afirmar que "nada tenho a ver" com o desmatamento, com a caça predatória, com os danos ao meio ambiente, com a poluição, pois pertencemos à mesma cadeia produtiva, nessas interligações e interdependências. Ao analisar essas configurações sociais na comunidade Afatam, elas também são inerentes nas redes de relacionamentos, nas interdependências; inter-relações entre os moradores; na observância do comportamento social; na socialização; no trabalho; nos escambos praticados; no comportamento entre eles.

\section{CONFIGURAÇÕES CEGAS OU ASPECTOS EVENTUAIS?}

Os autocontroles civilizadores, que desempenham um importante papel na vida das sociedades desenvolvidas, desenvolveram-se para o modelo que possuem agora, através de diversos processos modificadores. As estruturas sociais de "hoje" foram "moldadas" no "ontem", através de comportamentos que se incorporaram, instigando as transformações que acontecem na sociedade, mesmo que, no passado, não indicavam essas transformações. Por não serem perceptíveis quando ocorrem, denomina-se "configurações cegas".

Nesse contexto, os comportamentos sociais do "agora" podem influenciar, e modificar, os parâmetros sociais do "amanhã". São as configurações que, se antes eram denominadas "configurações cegas" hoje norteiam os nossos comportamentos (ELIAS e DUNNING, 1992, p. 167), quer seja no trabalho, no lazer ou mesmo nas relações familiares. Nesse viés do pensamento, analisamos os aspectos do êxodo rural dos jovens, em busca de "uma vida melhor", com relação aos estudos e profissão. Fato percebido não só na comunidade Afatam, mas por diversas outras comunidades em outros assentamentos, conforme falas que instigaram esta discussão no seminário Agroecológico da Universidade Federal do Amazonas - UFAM, ocorrido em dezembro/2015.

Ao pesquisar as classes de idade dos agricultores familiares da comunidade Afatam, observamos que, entre os 70 entrevistados, 43 estão na faixa etária entre 50 anos ou mais, representando 61,43\% da população pesquisada. Desses, 24 têm entre 60 a 77 anos, representando $31,17 \%$, formando a comunidade anciã. Ademais, dentre os 27 restantes que se encontram na faixa etária de 18 a 49 anos, representando $38,57 \%$, seis deles são caseiros, que a qualquer momento podem desligar-se do emprego, podendo (ou não) serem substituídos por outros em qualquer faixa etária, inclusive acima dos 50 anos.

Nas análises dos dados coletados, constatamos que a presença de jovens na comunidade pesquisada, principalmente após os 18 anos, possui pouca representatividade. Questionamos aos entrevistados: "Gostaria que seus filhos permaneçam morando no lote?". O desejo dos pais em que os filhos permaneçam na propriedade rural, para dar continuidade às suas atividades se apresentou em $3^{\circ}$ lugar. Para o $2^{\circ}$ lugar destacou-se o desejo dos pais de que os filhos também consigam lotes, para terem-nos por perto, com $21,43 \%$ e, destacadamente, o $1^{\circ}$ lugar, pelo motivo de que, nos assentamentos rurais, eles (os filhos) estariam mais afastados da violência, conforme Quadro a seguir: 
Tabela 1 - Desejo dos pais à permanência dos filhos na propriedade rural

\begin{tabular}{l|c|c}
\hline $\begin{array}{l}\text { Respostas escolhidas em 1\% lugar pelos 70 entrevistados na comunidade } \\
\text { Afatam }\end{array}$ & Qte & \multicolumn{1}{c}{$\%$} \\
\hline Sim. Sinto que aqui eles estarão mais afastados da violência & 15 & $42,86 \%$ \\
\hline Sim. Para eles conseguirem um lote também para si, e ficar por perto & 13 & $21,43 \%$ \\
\hline Sim. Para dar continuidade às minhas atividades na propriedade & 7 & $10,57 \%$ \\
\hline Não. Prefiro que eles vão pra cidade, estudar, se formar, ter uma vida melhor & 3 & $4,28 \%$ \\
\hline Não responderam, porque não tem filhos & 2 & $2,85 \%$ \\
\hline Não. Aqui a lida diária é muito difícil. Muito trabalho e pouco recurso & & 15 \\
\hline
\end{tabular}

Fonte: Pesquisa de campo (2016)

Ao analisarmos a obra de Abramovay (1998, p. 33), "Juventude e Agricultura Familiar: Desafios dos novos padrões sucessórios", acerca da influência dos pais para a opção profissional dos filhos, em que os pais estimulam os filhos a serem também agricultores, os resultados apresentaram que $72,20 \%$ entre os filhos que dão continuidade às atividades na agricultura, apresentando-se uma sucessão consolidada. No entanto, esta não representa a realidade da comunidade Afatam.

Seria esta uma configuração com probabilidades indicativas de comprometimento produtivo do Tarumã Mirim no futuro? Esse processo apresenta-se característico na Hinterlândia Amazônica "Hoje, filho ou filha de pescador, agricultor, piabeiro, seringueiro não seguem mais a formação dos pais, agora se tornam, entre outras profissões, professores" (MATOS, 2015, p. 50), devido ao fato, inclusive, da migração dos jovens para outros municípios, conclui Matos. Em diversos diálogos informais com alguns jovens à beira dos igarapés, eles relatavam:

Tia, aqui a vida é dura, num tem como a gente "crescer", num tem como estudar, se formar. Tem que ir simbora. Procurar melhoras fora daqui, onde os empregos podem ser mais do que uma mão de obra aqui, outra ali, uma capinada acolá, que é o que tem aqui no assentamento. A gente quer mais, quer ter mais oportunidades na vida.

Nesse contexto, perguntamo-nos: o que será do Tarumã Mirim (e dos assentamentos rurais na "hinterlândia" amazônica) daqui a 20, 30 ou 50 anos? Quem irá adubar a terra, plantar e colher? Escavar os tanques e criar peixes? Os anciãos já terão falecido, e os jovens já serão adultos que, se alcançarem o almejado de hoje, estarão formados, ou nos seus "empregos fixos", como é o sonho de muitos, não retornando ao seu território de origem. Será esta uma configuração cega, que futuramente representará uma comunidade constituída somente por "assentados do lazer", talvez formada por esses mesmos jovens, que ao interior se dirigirá, somente para o lazer no final de semana, na terra onde nasceram, cresceram, e precisaram abandonar, em busca de uma "vida melhor"?

\section{OBSERVANDO O PROCESSO CIVILIZADOR NA PESQUISA DE CAMPO}

$\mathrm{Na}$ pesquisa de campo que aconteceu no projeto de assentamento Tarumã Mirim, em diversas oportunidades pudemos observar o processo civilizador em suas nuances, nas mais diferentes situações: às margens dos igarapés; na lida nos seus roçados; no acampamento da associação de moradores; na vivência cotidiana das famílias. Isso nos permitiu apreender que em 
todos os contextos, as decisões "do eu" imbricava com a existência "do outro", nas interdependências e nas inter-relações sociais nos reportando, inclusive, aos ditos de Morin (1999) ao apontar que somos influenciados pelos pensamentos dos outros de tal modo que, apesar de independentes, dependemos das relações as quais construímos, e nos preocupamos inclusive com o que "o outro" pensa de nós e de nossas ações.

Isso porque os indivíduos estão interligados entre a nossa necessidade individual e a concepção coletiva, formando essas inter-relações sociais. Somos seres sociais, vivendo em uma interdependência, pois nos nossos relacionamentos dependemos do amigo, do colega, do vizinho, ou mesmo do desconhecido, porque para qualquer ação, é necessário que haja o outro. Cito a seguir alguns fragmentos pertinentes, detectando essa "preocupação social": (ENT-54, 70 anos) aqui em casa sempre tem um cafezinho pra gente ofertá pra visita, né? Sinão vão inté pensá qui a gente é miserave (miserável). Eu mermo num bebo, mas quem vem, bebe, intão num custa muito ser educado, num é mermo? Nóis num tá vivendo isolado, nós tem vizinho, cunhicido, parente [...].

Também observamos essas inter-relações e interdependências em quatro equipes da "Trupe da boia", formada por 15 mulheres (designadas pela sigla TRU-1 a TRU-15), no período de dois meses. Nesse período, elas cozinharam para a equipe de 20 trabalhadores da SEMINF que recuperava as vicinais, no acampamento improvisado na sede da associação da comunidade, denominado como "Acampamento da boia", na localidade pesquisada. Notamos que colaboração, interdependências e socialização formavam as inter-relações existentes, demarcando esse campo social: o preparo dos alimentos, a limpeza da sede, a distribuição de tarefas, etc.

Cito fragmentos do diálogo da líder da "Equipe Sargentão", no primeiro dia do seu "reinado" na cozinha comunitária: (TRU-12, 45 anos) vamo dexá tudo limpo e organizado. Daqui a pôco tão chegando pra cumê (comer)... E o qui eles vão pensar de nós, vendo essa bagunça toda qui dexamo, inquanto preparava o almoço? Que somo disorganizada? Qui é tudo de quarquer jeito?Qui só purque tamo na roça num temos educação? Nesse caso, percebemos a preocupação dela com o que "eles iriam pensar", porque a opinião "do outro" interfere nas ações "que eu pratico". Pudemos observar que outros membros, e outras equipes daquele acampamento, demonstraram comportamentos similares, norteando as suas ações. Em diversos outros momentos e situações também pudemos contatar essa preocupação constante: Relatamos aqui alguns fragmentos coletados nas entrevistas e nos diálogos captados:

(ENT-29, 71 anos) tô capinando aqui na prantaçãozinha de cubiu (maná cubiu - Solanum sessiliflorum). Pricisá num pricisa, pruquê esse matim (matinho) num atrapaia crecê nem pruduzí, mas chega gente aqui, vê o mato tomando diconta, vão pensa o quê? Qui tô morto de priguiça? Qui num sirvo pra nada? Ói dona, sempre fui hômi (homem) trabaiadô, num arrego pra nada não;

(ENT-63, 62 anos) Nóis num qué qui nossos fios (filhos) vão simbora, mais, si num dêxar, o qui os povo vão pensar dinós? Qui nóis tá cortando o distino deles? Atrapaiando o futuro mió deles? Si num dêxá, dispois vem a falação: num dexô pru ingoismo, pra ajuda na roça, mas pudia tá mió! Êsse povo fala dimais, mas, si nóis mora no meio, têm qui respeitá o qui o meio fala, sinão a gente fica falado.

(ENT-1, 42 anos) Se comportem, vocês são gente, não bicho. Parem de ficar gritando feito doidos... Até prece qui num dei educação procês...", ou 
"o que os outros vão pensar de vocês? E de mim? Qui são tudo criado a Deus dará? Sem eira nem beira? Sem freio?A gente mostra qui tem educação é no meio do povo, não só dentro de casa.

Na pesquisa de campo não foi observado somente essa preocupação latente com a opinião alheia, mas também com a rede de dependência existente entre os assentados, ou mesmo fora da territorialidade social. Essas interdependências e inter-relações estão tão imbricadas no ser humano, que não há como haver um isolamento social. Em diversos lotes visitados, percebemos essas interrelações: nos puxiruns, onde a mão de obra ofertada atende à demanda exigida, porque um ajuda o outro; nas comercializações das suas produções nas feiras de Manaus-AM, quando vendedor depende de comprador, que depende de consumidor, etc.

No Tarumã Mirim, a área de cada lote varia entre 1 a 4 ha, por estar classificada como pequena propriedade. Para maior aproveitamento, geralmente os assentados procuram preparar os locais de banhos nos igarapés, nas interligações dos lotes. Desse modo, ao se juntarem, tanto no trabalho (de prepará-los) quanto de apreciá-los nos momentos de lazer, esses banhos interligados formam "fontes" ricas em materiais para observamos o processo civilizador em todas as suas nuances. Para socializarem-se, uns comparecem com o peixe, outro com o suco, com o arroz, a farinha, e dessa socialização o lazer se manifestava regido pelo processo civilizador, nas interrelações sociais e nas interdependências entre eles.

Observamos também a percepção pessoal, instigada pelo social, que não é de "bom tom" os homens comparecerem na casa dos vizinhos sem vestirem uma camisa, ou às mulheres se visitarem de camisola. Esses mesmos homens que se constrangem em ir ao vizinho sem camisa e as mesmas mulheres que se recusam a aparecer em público de camisolas, comparecem nos igarapés usando minúsculos vestuários, onde todos comparecem. São comportamentos vivenciados em uma naturalidade rotineira, mas, ao afastarem-se do espaço geográfico denominado "banho", o corpo passa a representar o tabu, que deverá ser coberto pelo vestuário.

São regras aceitáveis por todos e normas preestabelecidas que foram incorporando-se nas condutas sociais. Essas configurações, quando do momento da sua ocorrência, às vezes não possui significado representativo, porem com o decorrer do tempo algumas situações alteram estruturas individuais e sociais. À medida que as pessoas compatibilizam suas condutas com a de outros indivíduos, eles são compelidos a nortear e modificar comportamentos anteriores, formando uma regulação social.

\section{CONSIDERAÇÕES FINAIS}

Ao analisar as configurações sociais na comunidade Afatam, no projeto de assentamento Tarumã Mirim, percebemos que, apesar de tratar-se de um contexto rural, elas também são inerentes nas redes de relacionamentos, nas interdependências entre os moradores, na observância do comportamento social, na civilidade entre os moradores, na socialização, pois nesses relacionamentos, um depende do outro. A vivência diária se incorpora às normas para um processo normatizador e civilizador, em uma interdependência social. O processo civilizatório encontra-se imbuído no seu próprio "eu" do caboclo. As restrições comportamentais são sinais de evolução social, pois aprenderam a controlar suas emoções e não se exporem em demasiado. As explosões apaixonadas, os descontroles emocionais, as demonstrações de excitamentos, tornam-se cada vez 
mais raros, até mesmo no seio do próprio círculo familiar, pois todos procuram reprimir suas emoções, até atingirem um patamar de autocontrole.

$\mathrm{Na}$ medida em que o homem se educa, se normatiza, absorve as normas de conduta socialmente aceitas, torna-se capaz de controlar seus impulsos, suas paixões, suas tensões, suas agressões, fazendo com que a convivência em sociedade se torne condizente com o seu tempo histórico, adequando-se aos comportamentos do século XXI, dentro dos parâmetros da atualidade. Isto é o autocontrole como fruto do processo educacional e civilizatório regendo e norteando comportamentos, quer perante a sociedade, quer perante a si próprio, pois até dentro do seu próprio quarto, há a presença intrínseca desse processo civilizador.

Com relação ao êxodo rural dos jovens na comunidade pesquisada, detectamos que são consequências macroestruturais, devido à ausência de investimentos na zona rural, que propiciem condições satisfatórias para que os jovens deem prosseguimento ao trabalho dos pais, na lida na terra, mantendo o processo sucessório. Os comportamentos do "ontem" se transformaram na sociedade do "hoje". Não seria este o momento adequado do "hoje" (e a tempo hábil), na comunidade Afatam, e consequentemente no projeto de assentamento Tarumã Mirim, despertar para novas possibilidades educacionais, econômicas e sociais, para formar um novo "amanhã"?

Instigar a implantação de polos educacionais universitário, com formação voltada para as ciências do campo, naquela localidade, corrigindo dois aspectos deficitários no Tarumã Mirim (educação e capacitações para tornar a terra produtiva), ou mesmo instigar o turismo de cercania, porque $\mathrm{o}$ assentamento citado possui três elementos imprescindíveis para tal: natureza ainda exuberante, abundância de águas e proximidade à Manaus. Tais procedimentos seriam uma "hemodiálise" socioeconômica, "injetando" sangue novo no projeto de assentamento Tarumã Mirim, de forma sustentável, com inovações, rompendo o ciclo do êxodo rural dos jovens, e fomentando perspectivas de um futuro diferente ao que ora desponta.

\section{REFERÊNCIAS}

ABRAMOVAY, Ricardo et al. Juventude e agricultura familiar: Desafios dos novos padrões sucessórios. Brasília: Unesco, 1998.

ALVES, Adjair. Treinando a observação participante: juventude, linguagem e cotidiano. Recife: Ed. Universitária de UFPE, 2011.

BALDINO, José Maria; LOURES, Patrícia Marcelina Loures; ALMEIDA, Maria Zeneide Carneiro Magalhães. A educação nas manifestações culturais populares religiosas: benzedores e a transmissão de saberes e "segredos". Caminhos. V. 13. n. 2, jul/dez 2015. Disponível em:< http://tede2.pucgoias.edu.br/index.php/caminhos/article/view/388-400/2464 .>Acessado em: 12 de abr. 2018.

BRASIL. Instituto Nacional de Colonização e Reforma Agrária - INCRA. Diagnóstico SócioEconômico-Ambiental do Projeto de Assentamento Tarumã Mirim. Manaus, 1999. Disponível em: <http://marte.sid.inpe.br/col/dpi.inpe.br/sbsr@80/2006/11.13.13.15/doc/3003-3009.pdf> Acesso em: 28 ago 2015.

ELIAS, Norbert. A sociedade dos indivíduos. Rio de Janeiro: Zahar, 1994.

O processo civilizador. Volume.1 Uma historia dos costumes. $2^{\underline{a}}$ ed. Rio de Janeiro, Zahar, 2011. 
O processo civilizador. Volume 2 Formação do Estado e Civilização. Rio de Janeiro: Zahar, 1993.

ELIAS, Norbert; DUNNING, Eric. A busca da excitação. Rio de Janeiro: Difel, 1992.

GEERTZ, Cliffort. A interpretação das culturas. Rio de Janeiro: LTC, 2008.

MALINOWSKI, Bronislaw. Argonautas do Pacífico ocidental: um relato do empreendimento e da aventura dos nativos nos arquipélagos da Nova Guiné melanésia. 2.ed. São Paulo: Abril Cultural, 1978

MATOS, G. C. G.. Ethos e figurações na hinterlândia amazônica. Manaus: Valer/FAPEAM, 2015.

MORIN, Edgar. Os sete saberes necessários à prática educativa. São Paulo: Cortez, 1999.

OLIVEIRA FILHO, João Pacheco de. Ensaios em antropologia histórica. Rio de Janeiro: Editora UFRJ, 1999.

PINTO, W. H. A; CARVALHO, A. S. C. Diagnóstico Sócio-Econômico-Ambiental do Projeto de Assentamento Tarumã Mirim. Manaus, 1999. In. Anais XIII SIMPÓSIO BRASILEIRO DE SENSORIAMENTO REMOTO, Florianópolis, Brasil, 21-26 abril 2007, INPE, p. 3003-3009. Geoprocessamento aplicado a análise físico-territorial da área do Tarumã - AM. Disponível em: <http://marte.sid.inpe.br/col/dpi.inpe.br/sbsr@80/2006/11.13.13.15/doc/3003-3009.pdf /marte.sid.inpe.br/col/dpi.inpe.br/sbsr@80/2006/11.13.13.15/doc/3003-3009.pdf.>. Acessado em: 12 de abr. 2018.

SANTOS, Saray Giovana dos (org). Métodos e técnicas de pesquisa quantitativa. Florianópolis: Tribo da ilha, 2011.

WHYTE, William Foote. Sociedade de esquina. Rio de Janeiro: Zahar, 2005. 